EXPERIMENTAL STUDY

\title{
Plasma and cerebrospinal fluid leptin levels are maintained despite enhanced food intake in progesterone-treated rats
}

\author{
Esther Grueso, Milagros Rocha and Marisa Puerta \\ Department of Animal Biology II (Physiology), Faculty of Biological Sciences, Complutense University, 28040 Madrid, Spain \\ (Correspondence should be addressed to M Puerta; Email: mpuerta@eucmax.sim.ucm.es)
}

\begin{abstract}
Objectives: For adipostatic control, increases in food intake are followed by increased leptin levels that in turn reduce food intake. However, progesterone administration increases both food intake and body weight. The aim of this study was to analyze changes in the white adipose tissue-leptin system in rats with enhanced plasma levels of progesterone.

Methods: Female Wistar rats received progesterone chronically by means of subcutaneous implants over 30 days.

Results: They showed an increased food intake followed by increased body weight and heavier fat depots. An enhanced $o b$-mRNA level was detected in inguinal white adipose tissue depot on day 2 of treatment but the increase was transient, disappearing on day 6 of treatment. No changes in $o b$-mRNA levels were found in parametrial and retroperitoneal white adipose tissue depots. Plasma and cerebrospinal fluid leptin levels were unchanged either during the treatment or between corresponding treated and control rats. Leptin concentrations in cerebrospinal fluid were ten times lower than in plasma $(0.2-0.3 \mathrm{ng} / \mathrm{ml}$ versus $2-3 \mathrm{ng} / \mathrm{ml}$ respectively).

Conclusions: These results indicated that progesterone favours a positive energy balance not only by enhancing food intake but also by inhibiting the concurrent enhancement in plasma and cerebrospinal fluid leptin levels expected from the increased fat mass.
\end{abstract}

European Journal of Endocrinology 144 659-665

\section{Introduction}

Since its discovery a few years ago, serum leptin has proved to be directly related to body fat in both humans $(1,2)$ and rats $(3)$. This has been considered to be the main evidence that it is a white adipose tissue (WAT) messenger signalling the size of the fat store to the central nervous system, in agreement with the adipostatic theory proposed by Kennedy (4) and sustained by Hausberger's experiments (5). On a short-term basis, leptin levels are also related to food-intake patterns so that, despite an essentially unchanged amount of WAT during a 24-h cycle, ingestive episodes increase leptin levels which reach a maximum during the active phase of the cycle, whereas no intake during the inactive phase of the cycle or fasting decreases it (6-8). Increased levels of leptin are also followed by increases in thermogenesis $(9,10)$. The whole picture is interpreted as leptin being the main signal for body fat store maintenance. There are, however, physiological situations where a positive energy balance is needed. This is the case during late pregnancy, when both food intake and body weight are increased (11). These changes are brought about by progesterone (12). However, this positive energy balance does not fit the adipostatic theory which, when running freely, would suggest that there is a corrective reduction in food intake to the hormonally driven increase in food intake and body weight gain. In this study, we have experimentally increased the plasma levels of progesterone to values similar to those reached at the end of pregnancy in order to analyze the modifications of the components of adipostatic control in such a situation.

\section{Materials and methods}

\section{Animal treatment}

Female Wistar rats, 180-200 g body weight, were acclimated to $28{ }^{\circ} \mathrm{C}$ (thermoneutrality) for $1-2$ weeks. On day 0 of the experiment $(214 \pm 1 \mathrm{~g}$ body weight), half of the animals received two progesterone-filled Silastic (Dow Corning, Midland, MI, USA) capsules (4 cm long; $3.2 \mathrm{~mm}$ outside diameter; $1.5 \mathrm{~mm}$ internal diameter). Control rats received empty implants. Capsules were inserted subcutaneously under ether anaesthesia. Rats were housed in individual cages with food and water available ad libitum and with a light:darkness cycle of $12 \mathrm{~h}$ light:12 h darkness with 
lights on at $0800 \mathrm{~h}$. The food provided was a commercial diet (Panlab, Barcelona, Spain) containing $66.7 \%$ carbohydrate, $19.3 \%$ protein, $3.4 \%$ fat, $4.9 \%$ cellulose and $5.7 \%$ mineral (by weight). Food intake and body weight were monitored daily during the first 2 weeks or every third day during the last 2 weeks. Food intake was measured by weighing what remained in the food cup. Animals were cared for and used in accordance with the principles of The Council of European Communities (86/609 EEC).

\section{Sample collection}

Both control and treated animals were killed by decapitation at different times during the experiment between 1100 and $1300 \mathrm{~h}$. Immediately before the animals were killed cerebrospinal fluid (CSF) was obtained under ether anaesthesia by inserting a 23 gauge butterfly needle into the cisterna magna and 100-120 $\mu \mathrm{l}$ CSF was gently withdrawn. Only samples without any blood contamination were processed. Vaginal smears were taken to determine the phase of the cycle in control rats and to corroborate the efficacy of treatment in progesterone-treated rats. Blood was collected in heparinized glass tubes $(10 \mathrm{IU} / \mathrm{ml})$. Inguinal, retroperitoneal and parametrial WAT depots were removed, weighed, frozen in liquid $\mathrm{N}_{2}$ and stored at $-80{ }^{\circ} \mathrm{C}$ until analysis.

\section{Detection of ob-mRNA}

Total cellular RNA was extracted using Ultraspec RNA reagent (Biotecx, USA), using a modified procedure of the method reported by Chomczynski \& Saachi (13) for total RNA isolation. RNA fractionation, blotting, hybridization and chemiluminescent detection were carried out according to Trayhurn et al. (14). In short, RNAs were fractionated by agarose gel electrophoresis, transferred to a positively charged nylon membrane (Roche Molecular Biochemicals, Mannheim, Germany) by capillary blotting and crosslinked with UV light using a Foto/UV 21 (Fotodyne, Hartland, WI, USA). The mRNA for the $o b$ gene was detected using a 33-mer antisense oligonucleotide probe $5^{\prime}$-labelled with a single digoxigenin ligand (5'-GGT CTG AGG CAG GGA GCA GCT CTT GGA GAA GGC-3'). The oligonucleotide had been synthesized commercially. The membranes were incubated sequentially with the oligonucleotide and with an anti-digoxigenin serum alkaline phosphataseconjugated antibody and processed essentially as in the protocols provided by Roche Molecular Biochemicals. CDP-star (Roche Molecular Biochemicals) was used as the chemiluminescent substrate. Signals were visualized by exposing the membranes to a film (Hyperfilm ECL; Amersham International plc, Amersham, Bucks, UK) and quantified by densitometry using Image I software (National Institutes of Health, USA). Membranes were stripped and reprobed for $18 \mathrm{~S}$ rRNA to check the loading and transfer of RNA during blotting. $18 \mathrm{~S}$ rRNA was detected using a 31-mer antisense oligonucleotide probe (5'-CGC CTG CTG CCT TCC TTG GAT GTG GTA GCC G-3').

\section{Hormone assays}

Blood was centrifuged at $2000 \boldsymbol{g}$ for $15 \mathrm{~min}$ at $4{ }^{\circ} \mathrm{C}$. Plasma was withdrawn and stored at $-80{ }^{\circ} \mathrm{C}$ until analysis. Plasma leptin levels were determined with a commercially available rat leptin radioimmunoassay (RIA) kit (Linco Research, USA). The limit of sensitivity for the assay was $0.5 \mathrm{ng} / \mathrm{ml}$, the limit of linearity being $50 \mathrm{ng} / \mathrm{ml}$. The intra- and interassay coefficients of variation were $4.6 \%$ and $5.7 \%$ respectively. CSF from either one rat or pooled from two rats was lyophilized. Samples were assayed by redissolving them in a smaller volume than the one indicated for plasma in the Linco kit. The other components of the kit were also reduced accordingly. The standard curve obtained with reduced volumes was validated with the quality controls as the values fitted their expected range.

Immunoreactive insulin was measured with the rat insulin RIA kit developed at Linco Research (St Charles, MO, USA). The limit of sensitivity for the assay was $0.1 \mathrm{ng} / \mathrm{ml}$ and the limit of linearity was $10 \mathrm{ng} / \mathrm{ml}$. The intra- and interassay coefficients of variation were $5.8 \%$ and $10.8 \%$ respectively. Plasma progesterone and corticosterone levels were determined with an RIA kit from DiaSorin (Vercelli, Italy) and an RIA kit from DRG Diagnostics (Marburg, Germany) respectively. The limit of sensitivity for the progesterone assay was $0.10 \mathrm{ng} /$ $\mathrm{ml}$ and the intra- and interassay coefficients of variation were $7.2 \%$ and $10.0 \%$ respectively and for corticosterone they were $7.1 \%$ and $7.2 \%$.

\section{Statistical analysis}

Kruskal-Wallis one-way analysis of variance (ANOVA) on ranks was performed to compare progesterone plasma levels between control and treated rats (the Dunn test being used post hoc) since data did not show Gaussian distribution. ob-mRNA levels in different depots of control rats and CSF leptin levels were tested using ANOVA with Student-Newman-Keuls test being used post hoc, whereas an unpaired Student's $t$-test was used for $o b$-mRNA comparison between control and treated rats. Food intake and body mass gain were evaluated by unpaired Student's t-test and MannWhitney $U$ test when data did not show Gaussian distribution. A two-way ANOVA was used for comparing plasma leptin levels, weight of WAT depots, plasma insulin and corticosterone levels. $P<0.05$ was considered to be statistically significant. 


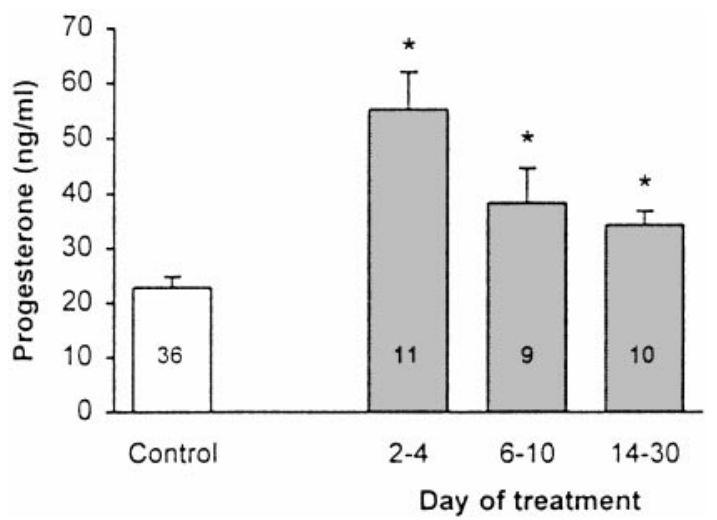

Figure 1 Levels of plasma progesterone in rats receiving the hormone chronically. Bars represent the mean \pm S.E.M. of the number of animals shown in the columns. ${ }^{*} P<0.05$ compared with control rats by a Kruskal-Wallis one-way ANOVA on ranks.

\section{Results}

The effectiveness of the hormonal treatment is depicted in Fig. 1 which shows that plasma progesterone levels in treated animals were two to three times those recorded in control animals, reaching values similar to those found at peak pro-oestrus (15) and in late pregnancy (16). The mean value in control rats represents an average value during the cycle since control animals were not all killed in the same phase of the oestrous cycle.

As expected, food intake was increased in treated animals from the first day of treatment and remained elevated for most of the treatment period (Fig. 2). Concurrently, body weight gain was greater in treated animals than in controls from the beginning of the treatment (Fig. 2) so that final body weight gain at day 30 was $21 \pm 3 \mathrm{~g}$ in control and $32 \pm 4 \mathrm{~g}$ in treated rats.

Progesterone treatment increased WAT depots weight although such increases did not attain statistical significance $(P=0.053)$ (Fig. 3). It should be emphasized that only the left half of every depot was measured so the real increase in the weight of every depot would be about twice the one depicted in Fig. 3.

$o b$-mRNA levels were measured in three different WAT depots, i.e. inguinal, parametrial and retroperitoneal. In control rats, no change was recorded in any depot during the treatment although comparison among depots showed that $o b$-mRNA levels were higher in the parametrial depot followed by the retroperitoneal depot, inguinal WAT having the lowest levels (Fig. 4A, open bars). Treated rats showed the same level of $o b$ mRNA as that in the respective controls in all the depots studied except in inguinal WAT at day 2 of treatment, which was greater in treated rats (Fig. 4).

Plasma leptin was unchanged in controls during the experiment, in agreement with previous results showing that leptin levels are unchanged during the
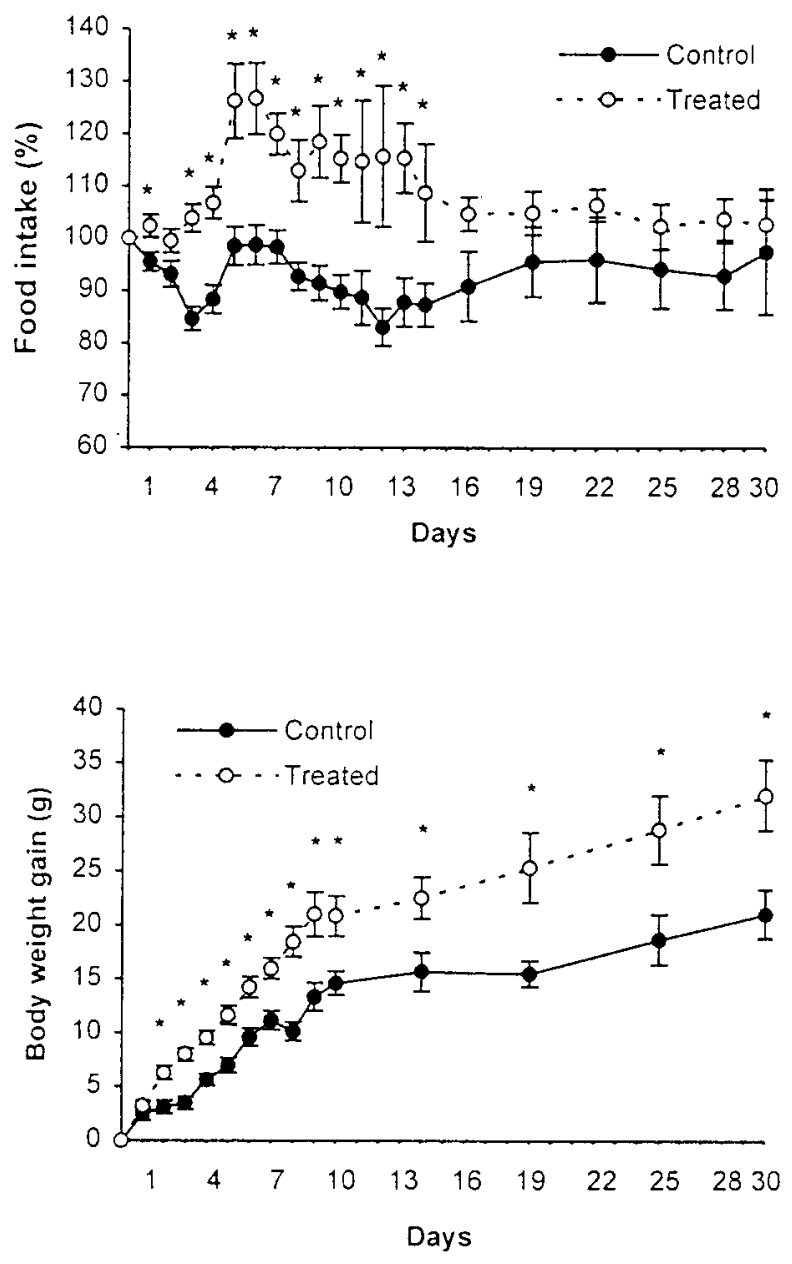

Figure 2 Daily food intake and body weight gain in rats receiving progesterone chronically (daily food intake is expressed as percentage of the daily food intake in the 3 days prior to the experiment). Each point represents the mean \pm S.E.M. of 48 animals at days $0-2,42$ at day 3,36 at day 4,30 at days $5-6,24$ at days $7-8,18$ at days $9-10,12$ at days $11-14$ and 6 at days $15-30$ in each experimental group. ${ }^{\star} P<0.05$ compared with the

respective control rats by Student's $t$-test or Mann-Whitney $U$ test.

oestrous cycle $(17,18)$. No changes were found after progesterone treatment (Fig. 5). CSF leptin values were ten times smaller than those found in plasma. None the less, no differences were found either during the treatment or between control and treated rats (Fig. 6).

Corticosterone levels on day 2 were twice those found on days 8 and 14 but there was no difference between control and treated rats. Insulin levels were also similar in control and treated rats (Table 1 ).

\section{Discussion}

Before the discovery of leptin, female sex hormones were known to influence both food intake and thermogenesis in the energy balance equation. Thus, progesterone administration to either ovariectomized or 

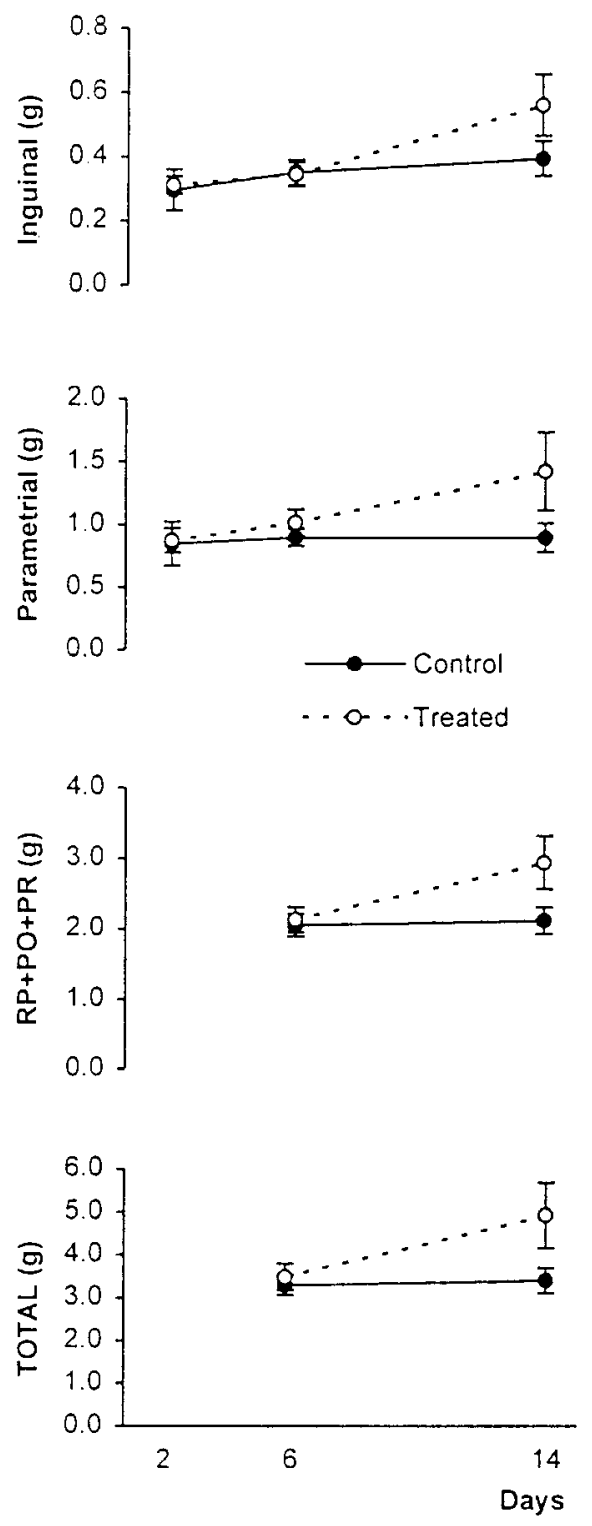

Figure 3 Weight of several WAT depots (the left half only) in rats receiving progesterone chronically. Each point represents the mean \pm S.E.M. of five to six rats. RP, retroperitoneal; PO, periovaric and PR, perirenal. No statistical differences were found between control and treated animals ( $P=0.053$ ) (two-way ANOVA).

intact rats increases food intake $(12,19,20)$ and decreases thermogenesis (21-23), thus rendering heavier animals. However, according to the adipostatic theory, increases in food intake would promote greater fat depots which, in turn, would produce higher leptin levels that would counterbalance the progesteroneenhanced food intake. Since this counterbalance does not take place in pregnant or progesterone-treated rats, we explored the in vivo changes in the WAT-leptin system in rats with experimentally increased levels of progesterone.
Our treated animals showed progesterone plasma levels similar to those of late pregnancy $(16,24)$ (Fig. 1). As expected, food intake increased during the entire treatment (Fig. 2), bringing about an enhanced body weight gain that was, at least in part (we did not measure fat-free mass), due to increased WAT mass (Fig. 3). If the adipostatic theory had been running freely, such positive energy balance would not have taken place. Therefore, it seems clear that the presence of progesterone hampered lipostatic control.

The route to signalling the amount of body fat begins with the synthesis and release of leptin from the white adipocytes. The molecule travels in blood to get into the CSF so that it reaches the hypothalamic centres involved in energy balance. All these three could be a step to impose a control to avoid adipostatic control by leptin. We measured $o b$-mRNA levels in different depots of WAT and - except for a transient increase in the inguinal depot at the early times of treatment (Fig. 4) no indication was found that there was any permanent enhancement in $o b$-mRNA, which suggests that no enhancement in leptin synthesis was taking place. However, since mRNA intracellular levels do not correlate unequivocally with protein synthesis and release, we measured the plasma levels of leptin to check if they were also unchanged and we found that they were (Fig. 5). This set of results - increased WAT depot, together with unchanged $o b$-mRNA levels and plasma leptin levels - demonstrated that adipostatic control was not running freely but was under progesterone control which was apparently impeding an increased leptin synthesis and release despite fat accumulation (the other possibility for maintaining plasma leptin unchanged - increased synthesis and increased degradation/excretion - does not seem to fit with the present results). Even so, there remained another possible target where progesterone might control signalling, i.e. interfering with leptin entrance in the CSF, since it is from this compartment that leptin reaches the hypothalamic centres involved in food intake and thermogenesis. Accordingly, we also measured leptin levels in CSF. Again, no change was recorded between progesterone-treated rats and untreated controls (Fig. 6), indicating that increased food intake in progesterone-treated rats could not be attributed to a diminished level of leptin reaching the hypothalamic centres. Therefore, the increased body weight and fat mass brought about by a progesteroneinduced increase in food intake can take place because no increase in leptin plasma or CSF levels occurs despite increased fat depot weight, as predicted to occur by leptin adipostatic control. In other words, progesterone seems to influence energy balance in a double manner. First, it stimulates undetermined orexigenic mechanisms that make the animals increase their food intake. Secondly, it acts peripherally at the level of the adipocytes, inhibiting any increase in the synthesis of leptin despite the concurrent enhancement in fat 
A
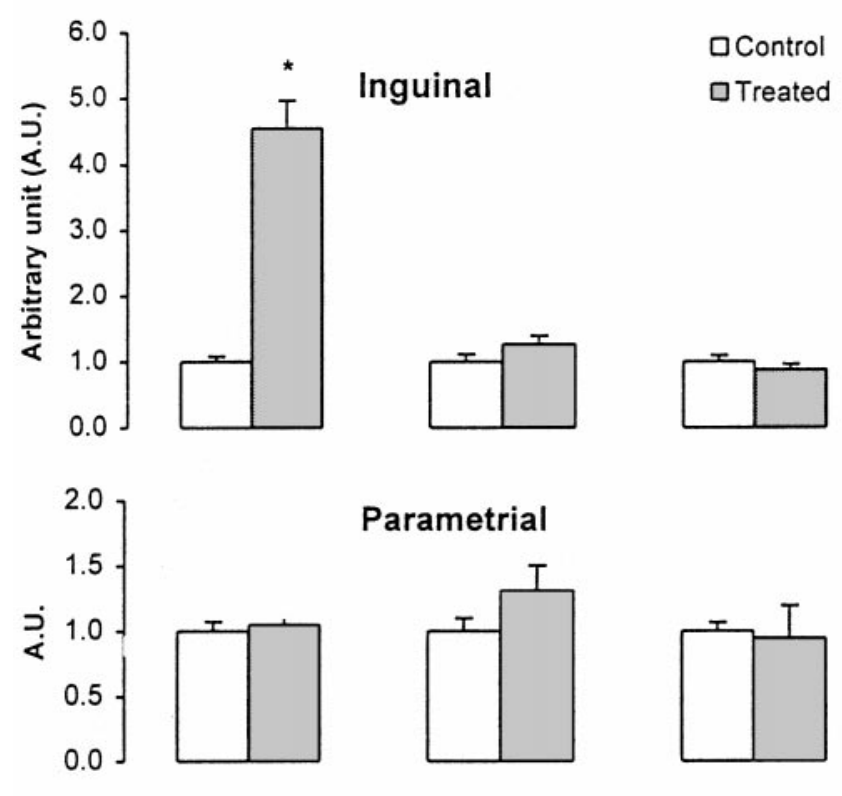

\section{Parametrial}
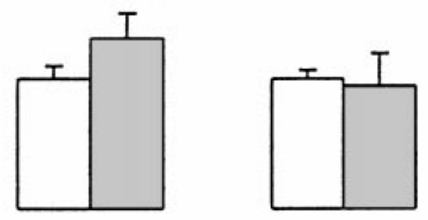
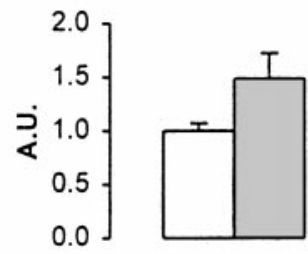

2

\section{Retroperitoneal}

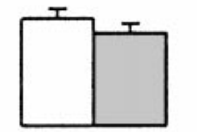

6

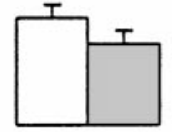

14 Days

B

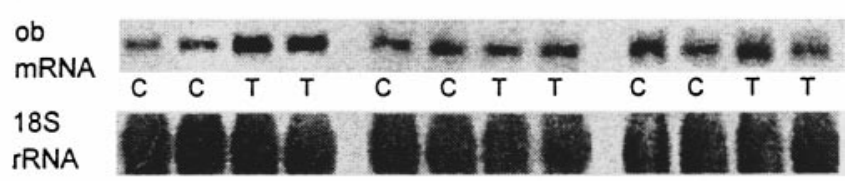

Figure 4 (A) ob-mRNA levels in different WAT depots of rats receiving progesterone chronically. The size of the arbitrary unit in every depot has been depicted proportionally to the arbitrary units in the others to allow comparison of basal levels among depots. Each column represents the mean \pm S.E.M. of five to six rats. ${ }^{*} P<0.05$ compared with the respective control rats by Student's $t$-test. No statistical differences were found among control groups (one-way ANOVA). (B) Northern blots of inguinal WAT at days 2, 6 and 14 of treatment. 18S rRNA was used to check loading and transfer. C, control; T, progesterone-treated. deposition. That such inhibition is taking place is further supported not only by the unchanged plasma leptin levels but also by the very high levels of $o b$-mRNA in inguinal depot in the 2-day sample, levels that decreased to those of controls at later stages of treatment. Probably, similar increases also occurred in the other WAT depots but were already suppressed at the time of our first sampling, i.e. $48 \mathrm{~h}$ after initiating

Table 1 Plasma corticosterone and insulin levels $(\mathrm{ng} / \mathrm{ml})$ in rats treated with progesterone chronically. Each point represents the mean \pm S.E.M. of the numbers shown in parentheses.

\begin{tabular}{lcccc}
\hline & Day 2 & Day 6 & Day 8 & Day 14 \\
\hline Insulin $(\mathrm{ng} / \mathrm{ml})$ & & & & \\
$\quad$ Control & $1.96 \pm 0.57(6)$ & $3.32 \pm 0.62(6)$ & - & $2.25 \pm 0.50(6)$ \\
$\quad$ Treated & $3.07 \pm 0.55(5)$ & $2.79 \pm 0.33(6)$ & - & $3.14 \pm 0.26(6)$ \\
Corticosterone $(\mathrm{ng} / \mathrm{ml})$ & & - & $487 \pm 58(5)$ & $426 \pm 56(5)$ \\
$\quad$ Control & $909 \pm 42(5)$ & - & $416 \pm 84(5)$ \\
$\quad$ Treated & $693 \pm 115(5)$ & & & \\
\hline
\end{tabular}

No statistical differences were found among groups (two-way ANOVA). 


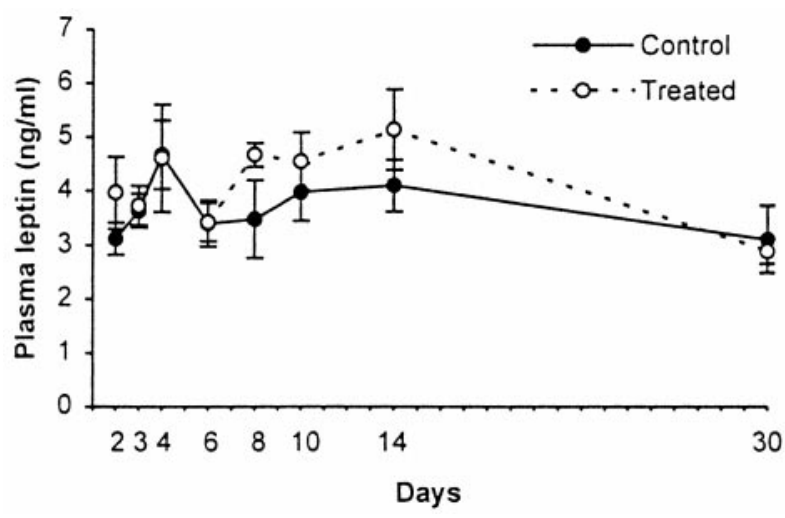

Figure 5 Plasma leptin levels in rats treated with progesterone chronically. Each point represents the mean \pm S.E.M. of six rats except on days 2, 6 and 14 when 12 rats were considered. No statistical differences were found among the groups (two-way ANOVA).

administration of progesterone. The confounding effects of insulin or corticosterone, which have been shown to alter leptin synthesis and release $(25,26)$, can be rejected since both control and treated animals showed the same plasma values for equivalent days. Results presented in this paper do not exclude progesterone modulating hypothalamic leptin sensitivity as a third mechanism to produce a positive energy balance. They are suggested both by the lower levels of mRNA encoding the leptin receptor isoform $o b$-Rb in the hypothalamus of pregnant rats (27) and by the changing levels of such mRNA (28) during the oestrous cycle which is known to show no alterations in plasma leptin levels $(17,18)$.

Since plasma progesterone levels increase steadily during pregnancy in both women (29) and rats (24) it seems logical to compare the results of this study with those dealing with leptin levels in pregnancy in order to cast light on the factors involved in determining plasma leptin levels during pregnancy. In women, most studies

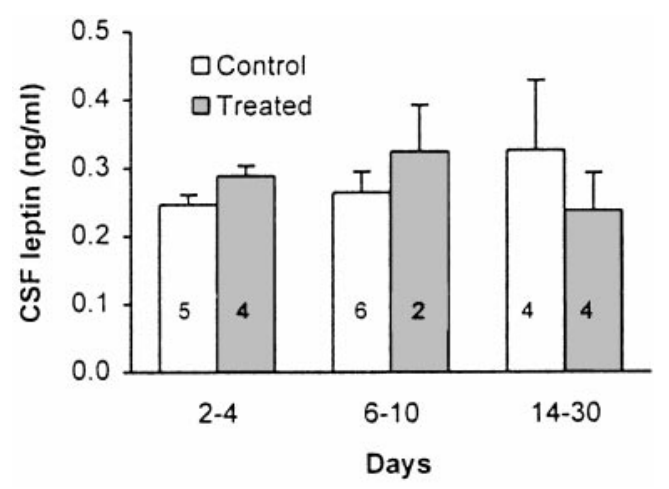

Figure 6 CSF leptin levels in rats treated with progesterone chronically. Each point represents the mean \pm S.E.M. of the number of samples shown in the columns. No statistical differences were found among groups (one-way ANOVA). have shown increasing plasma leptin levels during the first two trimesters of pregnancy with a sustained plateau during the third trimester (29-31). The inhibitory influence of progesterone could explain such a plateau since, during the third trimester, progesterone levels increase 100 times whereas during the first two trimesters they only increase four times. This allows the build up of a fat store for subsequent lactation. A similar role for progesterone can also be argued for rats since they also have increasing plasma leptin levels during pregnancy $(17,32)$. None the less, some authors have failed to detect any increase in leptin in pregnant rats (33).

Leptin concentration in plasma is well documented in both humans and rodents. To the best of our knowledge, there is only one result - obtained from one pool made up from three to four rats - concerning the leptin concentration in the CSF of rats (34), whereas there are a number of studies dealing with CSF leptin concentration in humans (35-37). We have obtained CSF from 38 rats which, after pooling, gave 25 results so our values demonstrate that leptin concentration in the CSF of rats is only ten times lower than in plasma, which is at variance with the 100 times lower values obtained in humans and in agreement with the previous report in rats (34). The significance of the higher values in the CSF of rats compared with those in humans suggests a differential sensitivity to leptin in the hypothalamus of both species, a suggestion that, however, needs to be confirmed experimentally.

\section{Acknowledgements}

This work was supported by grants 08.6/0007/1998 from Comunidad Autonoma de Madrid and PM980090 from Dirección General de Investigación Científica y Técnica to M P. M R was the recipient of a predoctoral fellow from Universidad Complutense de Madrid.

\section{References}

1 Pratley RE, Nicolson M, Bogardus C \& Ravussin E. Plasma leptin responses to fasting in Pima Indians. American Journal of Physiology 1997273 E644-E649.

2 Considine RV, Sinha MK, Heiman ML, Kriauciunas A, Stephens TW, Nyce MR et al. Serum immunoreactive-leptin concentrations in normal-weight and obese humans. New England Journal of Medicine1996 $334292-295$.

3 Greenberg JA \& Boozer CN. The leptin-fat ratio is constant, and leptin may be part of two feedback mechanisms for maintaining the body fat set point in non-obese male Fischer 344 rats. Hormone and Metabolic Research1999 31 525-532.

4 Kennedy GC. The role of depot fat in the hypothalamic control of food intake in the rat. Proceedings of the Royal Society Series B1953 140 578-592.

5 Hausberger FX. Parabiosis and transplantation experiments in hereditarily obese mice. Anatomical Record1958 130313.

6 Weigle DS, Duell PB, Connor WE, Steiner RA, Soules MR \& Kuijper JL. Effect of fasting, refeeding, and dietary fat restriction 
on plasma leptin levels. Journal of Clinical Endocrinology and Metabolism1997 82 561-565.

7 Ahima RS, Prabakaran D, Mantzoros C, Qu D, Lowell B, MaratosFlier E et al. Role of leptin in the neuroendocrine response to fasting. Nature $1996 \mathbf{3 8 2} 250-252$.

8 Pickavance L, Tadayyon M, Williams G \& Vernon RG. Lactation suppresses diurnal rhythm of serum leptin. Biochemical and Biophysical Research Communications1998 248 196-199.

9 Scarpace PJ, Matheny M, Pollock BH \& Tümer N. Leptin increases uncoupling protein expression and energy expenditure. American Journal of Physiology1997 273 E226-E230.

10 Wang T, Hartzell DL, Rose BS, Flatt WP, Husley MG, Menon NK et al. Metabolic responses to intracerebroventricular leptin and restricted feeding. Physiology and Behavior1999 65 839-848.

11 Abelenda M \& Puerta M. Inhibition of diet-induced thermogenesis during pregnancy in the rat. Pflügers Archiv. European Journal of Physiology1987 409 314-317.

12 Hervey E \& Hervey GR. The effects of progesterone on body weight and composition in the rat. Journal of Endocrinology 1967 37 361-384.

13 Chomczynski P \& Sacchi N. Single-step method of RNA isolation by acid guanidinium thiocyanate-phenol-chloroform extraction. Analytical Biochemistry1987 162 156-159.

14 Trayhurn P, Duncan JS, Nestor A, Thomas MEA \& Rayner DV. Chemiluminescent detection of mRNAs on northern blots with digoxigenin end-labelled oligonucleotides. Analytical Biochemistry1994 222 224-230.

15 Butcher RL, Collins WE \& Fugo NW. Plasma concentration of LH, FSH, prolactin, progesterone and estradiol- $17 \beta$ throughout the 4-day estrous cycle of the rat. Endocrinology1974 941704 1708 .

16 Devorshak-Harvey E, Bona-Gallo A \& Gallo RV. The relationship between declining plasma progesterone levels and increasing luteinizing hormone pulse frequency in late gestation in the rat. Endocrinology1987 120 1597-1601.

17 Amico JA, Thomas A, Crowley RS \& Burmeister LA. Concentrations of leptin in the serum of pregnant, lactating, and cycling rats of leptin messenger ribonucleic acid in rat placental tissue. Life Sciences 199863 1387-1395.

18 Watanobe H \& Suda T. A detailed study on the role of sex steroids milieu in determining plasma leptin concentrations in adult male and female rats. Biochemical and Biophysical Reseach Communications1999 259 56-59.

19 Richard D. Effects of ovarian hormones on energy balance and brown adipose tissue thermogenesis. American Journal of Physiology 1986250 R $245-\mathrm{R} 249$.

20 Nava MP, Abelenda M \& Puerta M. Cold-induced and dietinduced thermogenesis in progesterone treated rats. Pflügers Archiv. European Journal of Physiology1990 415 747-750.

21 Abelenda M, Castro C, Venero C \& Puerta M. Reduced oxygen consumption of brown adipocytes isolated from progesteronetreated rats. Canadian Journal of Physiology and Pharmacology1994 72 1226-1230.

22 Puerta M. Sympathetic tone and noradrenaline responsivenes of brown adipocytes from rats with high levels of sex steroids. In Temperature Regulation. Recent Physiological and Pharmacological Advances, pp 253-260. Ed AS Milton. Basel: Birkhäuser Verlag, 1994.

23 Ouevedo S, Roca P. Picó C \& Palou A. Sex-associated differencies in cold-induced UCP1 synthesis in rodent brown adipose tissue. Pflügers Archiv. European Journal of Physiology1998 436689 695.
24 Chien-Chen L, Tsai S-C, Wang S-W, Tsai C-L, Lau C-P, Shih H-C et al. Effects of ovarian steroid hormones and thyroxine on calcitonin secretion in pregnant rats. American Journal of Physiology1998 274 E246-E252.

25 Considine RV, Nyce MR, Kolaczynski JW, Zhang PL, Ohannesian JP, Moore JH Jr et al. Dexamethasone stimulates leptin release from human adipocytes: unexpected inhibition by insulin. Journal of Cellular Biochemistry1997 65 254-258.

26 Saladin R, Staels B, Auwerx J \& Briggs M. Regulation of ob gene expression in rodents and humans. Hormone and Metabolic Research1996 28 638-641.

27 García MC, Casanueva FF, Diéguez C \& Señarís RM. Gestational profile of leptin messenger ribonucleic acid (mRNA) content in the placenta and adipose tissue in the rat, and regulation of the mRNA levels of the leptin receptor subtypes in the hypothalamus during pregnancy and lactation. Biology of Reproduction2000 62 698-703.

28 Bennett PA, Lindell K, Wilson C, Carlsson LMS, Carlsson B \& Robinson ICAF. Cyclical variations in the abundance of leptin receptors, but not in circulating leptin, correlate with NPY expression during the oestrous cycle. Neuroendocrinology 199969 417-423.

29 Hardie L, Trayhurn P, Abramovich D \& Fowler P. Circulating leptin in women: a longitudinal study in the menstrual cycle and during pregnancy. Clinical Endocrinology1997 47 101-106.

30 Schubring C, Englaro P, Siebler T, Blum WF, Demirakca T, Kratzsch J et al. Longitudinal analysis of maternal serum leptin levels during pregnancy, at birth and up to six weeks after birth: relation to body mass index, skinfolds, sex steroids and umbilical cord blood leptin levels. Hormone Research1998 50 276-283.

31 Matsuda J, Yokota I, Iida M, Murakami T, Yamada M, Saijo T et al. Dynamic changes in serum leptin concentrations during the fetal and neonatal periods. Pediatric Research1999 45 71-75.

32 Chien EK, Hara M, Rouard M, Yano H, Phillippe M, Polonsky KS et al. Increase in serum leptin and uterine leptin receptor messenger RNA levels during pregnancy in rats. Biochemical and Biophysical Research Communications1997 237 476-480.

33 Terada Y, Yamakawa K, Sugaya A \& Toyoda N. Serum leptin levels do not rise during pregnancy in age-matched rats. Biochemical and Biophysical Research Communications1998 253 $841-844$.

34 Ishizuka T, Ernsberger P, Liu S, Bedol D, Lehman TM, Koletsky RJ et al. Phenotypic consequences of a nonsense mutation in the leptin receptor gene $\left(\mathrm{fa}^{\mathrm{k}}\right)$ in obese spontaneously hypertensive Koletsky rats (SHROB). Journal of Nutrition1998 128 22992306.

35 Schwartz MW, Peskind E, Raskind M, Boyko EJ \& Porte D Jr. Cerebrospinal fluid leptin levels: relationship to plasma levels and to adiposity in humans. Nature Medicine 19962 589-593.

36 Dotsch J, Adelmann M, Englaro P, Dotsch A, Hanze J, Blum WF et al. Relation of leptin and neuropeptide $\mathrm{Y}$ in human blood and cerebrospinal fluid. Journal of the Neurological Sciences1997 151 $185-188$.

37 Fujioka K, Patane J, Lubina J, Lau D, CSF leptin levels after exogenous administration of recombinant methionyl human leptin. Journal of the American Medical Association1999 282 1517-1518.

Received 25 October 2000

Accepted 12 February 2001 